\title{
Reconquistar los derechos humanos por la Unión Europea
}

\section{Recapture Human Rights by the European Union}

\author{
Carlos R. Fernández Liesa ${ }^{1}$ \\ Universidad Carlos III de Madrid (España)
}

Recibido: 12-10-20

Aceptado: $25-10-20$

\section{Resumen}

Este trabajo es una reflexión sobre los grandes desafíos de la UE en Derechos humanos. Se parte del papel histórico de Europa en los derechos humanos. Proponemos algunas medidas que se podrían adoptar para recuperar esa función. Asimismo, se identifican los principales problemas y las posibles soluciones. Por ejemplo, mantener la utopía de la modernidad, fortalecer la Unión social, ir contra el populismo y el nacionalismo, apoyar la sostenibilidad y la agenda 2030, entre otros.

Palabras-clave: Derechos humanos en la Unión Europea, Modernidad, Sostenibilidad, Desafíos en la UE.

\begin{abstract}
This work is a reflection of the great challenges of the European Unión in the field of human rights. We start from the historical role of Europe in human rights. We propose some measures to recover that role. In the same way we identify the main problems and possible solutions. Among other, maintain the utopia of modernity, strengthen the social union, fight against populismo and nationalism, help soustainibility and 2030 Agenda.
\end{abstract}

Key-words: Human rights in the European Union, Modernity, Soustainibility, Challenges in the European Union.

\footnotetext{
${ }^{1}$ (carlos@inst.uc3m.es) Catedrático de derecho internacional público de la UC3M. Este artículo forma parte del proyecto de Investigación Nuevos desafíos del derecho, del departamento de derecho internacional, eclesiástico y filosofía del derecho de la Universidad Carlos III de Madrid. Una muestra de su obra puede verse en la bibliografía de este mismo artículo.

ORCID: https://orcid.org/000-003-4499-4580.
} 


\section{Introducción}

Vamos a analizar algunas cuestiones de derechos humanos en la Unión Europea poniendo las luces largas, a vista de pájaro, para intentar identificar aquellos elementos que podrían permitir una reconquista de los derechos humanos en Europa, de tal manera que pudiera recuperar su rol de faro humanista que ilumina al resto del mundo, como tuvo durante mucho tiempo la Europa de las luces.

Recientemente el Papa Francisco I en la Carta Encíclica Fratelli Tutti sobre la fraternidad y la amistad social -de 3 de octubre de 2020- se fija en algunas tendencias del mundo actual contrarias a la fraternidad (capítulo primero, las sombras de un mundo cerrado) y cita, en primer lugar, a la integración europea, dentro de un primer epígrafe titulado Sueños que se rompen en pedazos. Incide en que en la actualidad "se encienden conflictos anacrónicos que parecían superados, resurgen nacionalismos cerrados, exasperados, resentidos y agresivos". Y señala que "el bien, como también el amor, la justicia y la solidaridad no se alcanzan de una vez para siempre; han de ser conquistados cada día". Aprovecho estas reflexiones que coinciden con el sentido de este artículo de reconquistar los derechos humanos como tarea básica de la Unión Europea.

Europa ha sido la patria de los derechos humanos, que luego se universalizaron. Siempre fue un faro para los derechos humanos, como se puede deducir del mimetismo con el que se crearon otros sistemas regionales de protección, o de los modelos constitucionales y universal de derechos humanos, que se basan en conceptos e ideas cuya cuna fue la cultura europea. Son un producto histórico europeo. Pero ese impulso creador se ha visto debilitado como consecuencia de la universalización de la sociedad internacional, que está incorporando otras visiones y concepciones que pueden poner en entredicho el patrimonio de los derechos humanos ya conquistado, así como también se ha visto afectado por el debilitamiento del proyecto político europeo de la Unión Europea, por la ampliación y por globalización. La reconquista de los derechos humanos sería para la Unión Europea un objetivo mediante el cual podría ser lo que fue, un referente internacional, lo que no es imposible si tiene voluntad de serlo.

\section{La necesidad de reforzar la protección de los derechos humanos en la Unión Europea}

En Europa existen varios sistemas de protección de los derechos humanos. El nivel constitucional de cada Estado se ve complementado por la supervisión, 
para los 47 Estados miembros, del Tribunal europeo de Derechos humanos. Además, los 27 Estados miembros de la Unión Europea forman parte de un sistema especial de protección, al margen del mecanismo de la Organización de seguridad y cooperación y seguridad. Cada mecanismo internacional de supervisión responde a lógicas y a ordenamientos jurídicos distintos.

El sistema del Consejo de Europea $^{2}$ era el resultado de la creación de esta organización en Londres, el 5 de mayo de 1949, que inspiró el ideal de unificación europea tras la segunda guerra mundial, a través de los derechos humanos. Este objetivo ha dado lugar a los mayores avances en derechos humanos que se han producido en la Comunidad internacional y ha servido de parámetro de inspiración de otros sistemas regionales. Cabe plantearse cuáles deben ser los nuevos horizontes para que el sistema europeo siga siendo un motor para la protección internacional de los derechos humanos. La ampliación a los países del este pone en el tablero la relevancia del modelo democrático y de derechos humanos de sus Estados miembros, que depende no solo del convenio sino de cuestiones políticas que exceden de la labor del tribunal y que ponen en riesgo el principio democrático y la defensa de los derechos humanos.

Pero en este análisis nos centraremos en la Unión Europea, que es diferente porque los derechos humanos no eran algo en lo que hubiesen pensado los padres fundadores, pues el objetivo de la organización era de naturaleza económica. Ello no obstante desde el principio hubo dos artículos que contenían tanto el principio de libre discriminación por razón de nacionalidad como el principio de no discriminación por sexo, vinculados a derechos humanos. En este caso era porque la realización del mercado exigía una igualdad entre las personas jurídicas o físicas con independencia de la nacionalidad, para asegurar la libre competencia y el principio de libre circulación de los factores del mercado.

En una primera fase jurisprudencial el TJUE no reconocía la vinculación de las Instituciones con los derechos fundamentales, aun siendo evidente la falta de coherencia que supone el que se cedan competencias estatales a una organización que conlleven una reducción de las garantías constitucionales de los ciudadanos. En el asunto comptoirs de vente indicó el Tribunal que "no le corresponde asegurar el respeto de las reglas de derecho interno, incluso constitucionales, en vigor en uno u otro Estado miembro"3. Esa falta de coherencia y homogeneidad daría lugar a la rebelión de los tribunales constitucionales alemán e italiano

${ }^{2}$ Sobre este sistema ha habido múltiples estudios y análisis. Vid en una aproximación Fernández Sánchez, P.A., La obra jurídica del Consejo de Europa (En conmemoración del 60 aniversario del Consejo de Europa), VVAA, Sevilla, Ed. Gandulfo, 2010; Fernández Sánchez, P.A., García Roca, F.J., Integración europea a través de derechos fundamentales: de un sistema binario a otro integrado, VVAA, Centro de estudios políticos y constitucionales, Madrid, 2009; Ripoll Carulla, S., Ugartemedía, J.I., España ante los tribunales internacionales europeos: cuestiones politica judicial, Instituto vasco de administración pública, 2008

${ }^{3}$ En el mismo sentido Asunto Stork 1/58, Rec. P. 47; Asunto Prasident, asuntos 36, 38/59; Asunto Sgarlata, 49/64.

Araucaria. Revista Iberoamericana de Filosofia, Política, Humanidades y Relaciones Internacionales, año $22, \mathrm{n}^{\circ} 45$. Tercer cuatrimestre de 2020. Pp. 27-50. ISSN 1575-6823 e-ISSN 2340-2199 https://dx.doi.org/10.12795/araucaria.2020.i45.02 
que cuestionaron la validez de los actos comunitarios que no eran respetuosos con los derechos fundamentales constitucionalmente reconocidos. Esto ponía en peligro el principio de primacía del derecho comunitario sobre el nacional.

Este es el origen del modelo pretoriano de protección de los derechos humanos. El método que se utilizará para la incorporación de los derechos fundamentales será acudir a los principios generales de derecho comunes a los sistemas jurídicos de los Estados miembros, que se nutre mediante el recurso a los propios ordenamientos jurídicos nacionales y al ordenamiento internacional. Este activismo judicial dio lugar a un conocido modelo pretoriano. Desde el Tratado de Maastricht, de 1992 se entra en un proceso de positivación progresiva de los derechos fundamentales, cuyos principales hitos están en el art. F. 2 del TUE, en el Tratado de Amsterdam, en la Carta de derechos fundamentales proclamada en Niza (2000) y en el tratado de Lisboa de 2007, donde la carta pasa a tener valor jurídico como derecho primario, aunque el art. 6 se remita a ella mediante un reenvío, lo que deterioraba su fuerza política. En Niza se proclama la Carta de derechos fundamentales de la UE como un documento de valor político, sin fuerza vinculante, pero con un valor político expansivo para el proyecto europeo.

El Tratado constitucional incluyó la Carta en la segunda parte, lo que situaba a los derechos humanos en un lugar de honor, con alto significado jurídico, pero también político, en la construcción europea, con un potencial expansivo. Los ciudadanos se identifican con los derechos. El fracaso y el posterior rescate constitucional por el Tratado de Lisboa redujo su visibilidad, pero no su valor jurídico, al incorporarse por referencia, en virtud del art. 6, 1 que indica: "La Unión reconoce los derechos, libertades y principios enunciados en la Carta de los derechos fundamentales de la Unión Europea de 7-XII-2000, tal como fue adaptada el 12 de diciembre de 2007 en Estrasburgo, la cual tendrá el mismo valor jurídico que los Tratados". El rescate constitucional debilitó los derechos humanos.

El TJUE utiliza la Carta de derechos fundamentales como parámetro de interpretación y de legalidad de los actos de derecho derivado. El modelo de protección es descentralizado, de tal modo que los jueces nacionales actúan como jueces de derecho comunitario en la aplicación. La aplicación de la carta de derechos fundamentales por los jueces nacionales se realiza en relación con los actos de las instituciones y de los órganos de la Unión (por ejemplo, una directiva) y/o cuando los Estados aplican el derecho de la Unión por sus administraciones nacionales. En todo caso para que se aplique la Carta tiene que haber un vínculo con el derecho de la Unión. La carta tiene en esos casos primacía, es invocable por los particulares y las normas deben ser interpretadas de acuerdo a la misma; en el supuesto en que no sea así habría una responsabilidad del Estado. En caso de duda cabe realizar cuestiones prejudiciales sobre su 
interpretación. Además, el Tratado preveía la adhesión de la UE al CEDH (art, 6,2). Ahora bien, el dictamen del tribunal de Justicia de la UE de 18-XII-2014 dejó clara la imposibilidad de dicha adhesión.

Desde una perspectiva amplia este modelo plantea muchas cuestiones. ¿Puede un modelo de derechos humanos que predica la indivisibilidad seguir teniendo niveles de desigualdad social tan grandes como las existentes entre los Estados, sin resultar deslegitimado? Cierto que el modelo social europeo es envidiable internacionalmente, pero en el espacio intraeuropeo está creciendo a marchas forzadas la desigualdad. ¿No exigiría la integración europea un paso adelante en la Europa social, más allá de que la garantía de los derechos sociales dependa de los Estados? Del mismo las violaciones de las premisas básicas del Estado de derecho en la Unión Europea no están siendo suficientemente garantizadas, y se ha producido un deterioro de la democracia como resultado de los populismos y de los nacionalismos. Cuestiones como estas exigen nuevos planteamientos en derechos humanos en la Unión Europea que no se han hecho por el aumento de partidos extremistas que han llevado a poner en peligro el proyecto europeo y han condicionado sus ambiciones.

El sistema de protección de derechos humanos en la Unión Europea resulta de circunstancias histórico-políticas muy específicas. Como dijera Bobbio ${ }^{4}$ los derechos nacen dónde y cuándo pueden. En la Unión Europea se hizo de la necesidad virtud. La vuelta a la interestatalidad de muchos Estados, como consecuencia de la crisis constitucional, de la globalización y de la ampliación han frenado el proceso de integración y el lugar de los derechos humanos en la construcción europea. Tal vez la pandemia pueda ser un escenario que finalmente lleve a una mayor solidaridad europea si se sale bien de la misma.

En la Unión Europea la xenofobia y el racismo con los extranjeros y aún en algunos casos con los nacionales y los problemas derivados del nacionalismo no han sido objeto de políticas y estrategias que permitan que la sociedad se oriente a una convivencia bajo fórmulas humanistas. El sistema de protección parece neutro ante tales cuestiones, lo que no es ajeno al carácter en exceso técnicojurídico del modelo, alejado de la idea de ciudadanía y de estrategias políticas de aplicación. Es un sistema de mínimos que no cumple bien con la función objetiva de los derechos humanos, en tanto que principios inspiradores de la labor de los poderes públicos, sino que pretende limitar su papel a no violarlos directamente. Es un modelo poco inspirador de políticas públicas y desconocido por la ciudadanía, en la sociedad del homo videns, por lo que su fuerza real está debilitada. Habría que desarrollar planes y estrategias de derechos humanos, y hacer una labor de impulso europeo supranacional en los problemas más graves (desigualdad, nacionalismo tribal, xenofobia con los extranjeros, cultura de pluralismo y respeto a la diversidad en los modelos de convivencia ...).

${ }^{4}$ Bobbio, N., El tiempo de los derechos, Editorial sistema, Madrid, 1991, 255 pp.

Araucaria. Revista Iberoamericana de Filosofia, Política, Humanidades y Relaciones Internacionales, año 22, $\mathrm{n}^{\circ} 45$. Tercer cuatrimestre de 2020. Pp. 27-50. ISSN 1575-6823 e-ISSN 2340-2199 https://dx.doi.org/10.12795/araucaria.2020.i45.02 
Además, la globalización ha tenido un impacto sistémico. Percibida inicialmente como un factor positivo para la universalización de los valores, los derechos y el modelo democrático, décadas después ha debilitado al Estado, principal garante de los derechos. Ha mostrado frente a la retórica de la indivisibilidad la realidad de la invisibilidad de algunos derechos, en palabras de Carrillo Salcedo 5 . Esto es predicable también de la Unión Europea, que necesitaría impulsar dimensiones de Estado social si quiere ser un proyecto sostenible para los ciudadanos europeos, que no vean en la misma una construcción de los mercados, sino un reconocimiento y una protección de sus derechos. Sería la mejor receta para la desigualdad creciente en un mundo donde solo un $15 \%$ de la población tiene ingresos altos. La convergencia no es sencilla ${ }^{6}$, ni en la propia Unión Europea; los índices de desigualdad van a peor en muchos países?

\section{Mantener la utopía de la modernidad}

La Unión Europea es un resultado del sueño kantiano de la paz a través del Derecho. Tanto la creación de la Comunidad europea del Carbón y del acero, en 1952, como de la Comunidad Económica europea y de la Euratom (1957) buscaban reemplazar el enfrentamiento y los nacionalismos que habían llevado a dos guerras mundiales, por la cooperación. La fórmula fue un verdadero éxito, heredero de la utopía y los ideales de la modernidad, entre los que en el centro está la protección de los derechos humanos. En las primeras décadas el proyecto no incorporaba directamente los derechos humanos, pero lo hacía implícitamente y en todo caso fue un éxito desde la perspectiva de la paz, el progreso económico y el bienestar de los ciudadanos, en la edad de oro de la economía europea, lo que llevaría a que la construcción europea fuese vista como una garantía de éxito de la democracia y los derechos humanos.

Ese escenario ya no existe por las crisis económicas y por el desplazamiento de Europa del centro del mundo. Por ello para seguir manteniendo la utopía de la modernidad la Unión Europea debería cambiar de estrategia, si es que quiere seguir manteniendo el legado de la Ilustración tanto en su construcción interna como en su dimensión internacional. Se tiende a minusvalorar ese legado, en la búsqueda de nuevos proyectos utópicos, siempre sugestivos. Hay que tener cuidado con acabar con la utopía de la modernidad sin haber llegado a ella, en espera de una revolución. La revolución no deja de ser -indica Peces-Barbauna "secularización de la idea cristiana de redención, que ha introducido,

\footnotetext{
${ }^{5}$ Carrillo Salcedo, J.A., Globalización y orden internacional, Lección inaugural leída en la solemne apertrua del curso académico 2004, 2005, de la Universidad de Sevilla, Sevilla, 2004, pp. 15 ss

${ }^{6}$ Sachs, J., La era del desarrollo sostenible, Paidós, 201, 604 pp, pp. 70 ss, p. 93.

${ }^{7}$ Ferrajoli, L., Manifiesto por la igualdad, Editorial Trotta, 2019, pp. 69 ss.
} 
paradójicamente, el infierno en la tierra". Algunas utopías como las que llevaron al comunismo fueron implantadas y sostenidas en graves crímenes contra la humanidad como los gulags en la época de Stalin ${ }^{9}$. Impugnar la modernidad por valores alternativos que exaltan la nación, la religión, el poder y la privacidad que no se integran en una propuesta unitaria expresa un caos cultural $^{10}$.

Buena prueba de ello es que atacar la modernidad en los países árabes ha acabado apuntalando a las dictaduras teocráticas. La utopía ha dado paso a la revancha de Dios ${ }^{11}$, a que los movimientos de reislamización en el mediterráneo hayan tomado el relevo a los grupos marxistas. Desde la teoría crítica algunos autores deslegitiman los derechos humanos y lo consideran un "elemento central de las matrices de subordinación", un "factor social de dominación y de explotación", junto a otros como el racismo, el patriarcado, el capitalismo o el imperialismo ${ }^{12}$; el sistema normativo de protección de los derechos humanos no sería sino una forma de dominación y de que occidente civilice al tercer mundo con los propios valores culturales. Esta crítica se ha visto muy extendida desde visiones políticas y teóricas extremas, a ambos lados del espacio político, al considerar que la Unión Europea es una construcción neoliberal que se olvida de los derechos humanos en aras al único interés del mercado.

No comparto esa visión de Europa, cuya construcción constituye una necesidad. Pero en esa construcción los derechos humanos deben fortalecerse si se quiere que el proyecto no se debilite o perezca. La Unión Europea debería apostar por defender los ideales de la Ilustración, frente a otras tendencias. Pinker analiza la validez de los ideales de la Ilustración en el mundo actual, en tanto que productos de la razón humana, en pugna con otras facetas de la naturaleza humana (lealtad a la tribu, deferencia a la autoridad, pensamiento mágico...). El relato antimoderno dice que las Instituciones de la modernidad han fracasado. Los ideales de la Ilustración, indica, debe ser defendidos frente a otros. Bien haría la Unión Europea en defender el legado de la modernidad ${ }^{13}$ frente al populismo y al nacionalismo, renovando el lenguaje y los conceptos para el siglo XXI.

${ }^{8}$ Peces-Barba, G., Etica, poder y derecho. Reflexiones ante el fin de siglo, Centro de estudios constitucionales, 1995, p. 13.

${ }^{9}$ Vid. Applebaum, A., Gulag. Historia de los campos e concentración soviéticos, Editorial Debate, 2004, 665 pp.

${ }^{10}$ Peces-Barba, Etica, poder y derecho, ib.

${ }^{11}$ Vid. Kepel, H., La revancha de Dios, Ciencia política, Alianza Editorial, 2005, pp. 24 ss.

${ }^{12}$ Esta es la tesis de Bachand, R., Les subalternes et le Droit international, Ed. A Pedone, Paris, 2018, pp. 183, 187

${ }_{13}$ En este sentido Pinker, S., En defensa de la Ilustración, Paidós, 2018, p. 25, analiza la validez de los ideales de la Ilustración en el mundo actual, enb tanto que productos de la razón humana, en pugna con otras facetas de la naturaleza humana (lealtad a la tribu, deferencia a la autoridad, pensamiento mágico..). El relato antimoderno vendría a decir que las Instituciones de la modernidad han fracasado. Los ideales de la Ilustración, indica, debe ser defendidos frente a otros

Araucaria. Revista Iberoamericana de Filosofia, Política, Humanidades y Relaciones Internacionales, año $22, \mathrm{n}^{\circ} 45$. Tercer cuatrimestre de 2020. Pp. 27-50. ISSN 1575-6823 e-ISSN 2340-2199 https://dx.doi.org/10.12795/araucaria.2020.i45.02 
La denominada teoría crítica busca superar el dominio y la represión. Theodor Adorno y M Horkheimer, autores de la Dialéctica de la Ilustración y padres fundadores de esta corriente buscan hacer patente la naturaleza legitimatoria de la actual ideología dominante sobre la realidad opresiva del capitalismo desarrollado ${ }^{14}$. Ciertamente que como en cualquier orden el de la Unión Europea resulta de las relaciones de poder y que está crítica tiene elementos de apoyo al enjuiciar la construcción europea. Pero hay que prevenirse de ir contra el proyecto europeo sin tener un proyecto alternativo mínimamente sólido. Es como ir contra el consenso constitucional sin haber trabado un mayor consenso para la reforma. Sin duda que la UE es mejorable, como venimos manteniendo en este trabajo, pero constituye un paso adelante en un camino en el que falta mucho por hacer.

El modelo de legitimidad del poder en la Unión Europea, en ausencia de un Estado, es más de legitimación, en el sentido de Habermas ${ }^{15}$, de que responda a las necesidades de cohesión del sistema, desde el punto de vista social. Esa legitimación se produce si sirve para disminuir la distancia entre la realidad y las necesidades. Si esto no sucede se produce una crisis de racionalidad en el sentido de incompatibilidad entre lo que predican los derechos humanos y otras normas del mismo subsistema, con en la Unión Europea las de derecho económico.

En este sentido, la respuesta europea a la pandemia del coronavirus ha sido más solidaria de la que se produce en el escenario internacional. Hubo un primer momento de vuelta a los nacionalismos y de reforzamiento de la interestatalidad, que todavía tiene mucha inercia. Pero no cabe desdeñar el valor que, para la solidaridad, visto en perspectiva internacional, tiene la aprobación de los programas de subvenciones y créditos por 750.000 millones de euros, y de un conjunto de medidas adoptadas por las instituciones europeas para favorecer la recuperación económica y también el mantenimiento de la Unión Europea y de un mínimo de solidaridad ${ }^{16}$.

Es un ejemplo de cómo la Unión Europea debería hacer más para reforzar su legitimidad impulsando una respuesta a los problemas de los derechos humanos. En este sentido se debería reforzar la protección de los derechos sociales y de un mínimo social europeo que supondría un paso adelante de la Unión Europea. De otro lado el reto de afrontar la extranjería desde una perspectiva integradora, eliminado la xenofobia y erradicando una aproximación contraria a los extranjeros, que no es acorde con una visión humanista ni de derechos humanos ni con los propios intereses europeos y nacionales, dada la evolución demográfica.

\footnotetext{
${ }^{14}$ González Soriano, J.A., "La teoría crítica de la Escuela de Frankfurt como proyecto histórico de racioanlidad revolucionaria”, Revista de filosofía, vol. 27, n² 2, 2002, pp. 287-303, p. 290.

${ }_{15}$ Habermas, J., Escritos sobre moralidad y eticidad, Paidós, 1991, p. 132.

16 Vid. el número monográfico de la Revista Tiempo de Paz, 137 sobre el Covid 19 (verano de 2020)
}

Araucaria. Revista Iberoamericana de Filosofia, Política, Humanidades y Relaciones Internacionales, año $22, \mathrm{n}^{\circ} 45$. Tercer cuatrimestre de 2020. Pp. 27-50. ISSN 1575-6823 e-ISSN 2340-2199 https://dx.doi.org/10.12795/araucaria.2020.i45.02 
La Unión Europea es un ejemplo de organización internacional en la que el derecho debe tener una función transformadora de la realidad social, en sentido solidario. La evolución futura de la Unión Europea debe profundizar en los valores y los derechos humanos de modo tal que los ciudadanos se identifiquen y pueda tener un efecto impulsor para los derechos humanos, no solo las políticas monetarias y económicas o para el régimen de los mercados.

\section{Renovar el fundamento de la dignidad.}

En la Unión Europea la noción de dignidad aparece en disposiciones del Tratado de Unión y de la Carta de derechos humanos, lo que refleja su prestigio. La dignidad ${ }^{17}$ encuentra sus semillas en el pensamiento clásico ${ }^{18}$ en autores como Platón, Aristóteles, Cicerón, Horacio, Terencio o Séneca, que habían establecido algunas premisas previas de fundamentación posterior, como el ideal de autonomía (el cuidado de sí) (epimeleia heautou, cura sui), el sapere aude (atrévete a servirte de tu propia razón), el carpe diem (la búsqueda de la felicidad individual) y el ideal de ciudadano del mundo, la igualdad moral del ser humano (y el homo homini, sacra res).

Luego esta idea se renueva en la modernidad, donde la construcción de los derechos humanos es deudora de ella. En la modernidad el hombre aparece como centro del mundo, desde una visión antropocéntrica, que va secularizando el orden y que está en la base de los derechos humanos, que se desarrollan luego en la Ilustración y donde, por ejemplo, los ríos o los animales no podrían ser sujetos de derecho. Los mimbres del Derecho son difíciles de cambiar. En el plano internacional la dignidad se considera fundamento del Derecho internacional de los derechos humanos. Y en el plano constitucional la Carta magna indica, en el art. 10, 1 que "la dignidad humana, los derechos inviolables que le son inherentes, el libre desarrollo de la personalidad, el respeto a la ley y a los derechos de los demás son fundamento del orden político y de la paz social".

En la Unión Europea la dignidad humana aparece no solo en la carta de derechos humanos, en tanto que título del primer capítulo, donde aparecen las normas de Ius cogens, que establecen una jerarquía de valores, sino también como un derecho, mientras que el tratado de Lisboa establece que la Unión se fundamenta, junto a otros, en los valores de respeto a la dignidad humana (art 2 TUE), que también constituye un principio de la acción exterior (art. 21.1), una condición de adhesión (art 49) y de permanencia como miembro de pleno derecho (art.7).

\footnotetext{
${ }^{17}$ Vid. sobre esta noción Peces-Barba, G., La dignidad de la persona humana desde la filosofía del derecho, DYkinson 2002, pp. 12 ss.

${ }^{18}$ Pele, A., La dignidad humana. Sus orígenes en el pensamiento clásico, Instituto de derechos humanos Bartolomé de las Casas, Dykinson, 2010, 757 pp.
}

Araucaria. Revista Iberoamericana de Filosofia, Política, Humanidades y Relaciones Internacionales, año $22, \mathrm{n}^{\circ} 45$. Tercer cuatrimestre de 2020. Pp. 27-50. ISSN 1575-6823 e-ISSN 2340-2199 https://dx.doi.org/10.12795/araucaria.2020.i45.02 
El carácter abierto de la noción permite esa plasticidad, que discurre hacia nuevos derroteros y que puede complementarse. Recientemente, a principios del siglo XXI la idea de dignidad ha llevado a la aparición del Derecho de la discapacidad, nueva rama del derecho ${ }^{19}$; la idea de dignidad sirve para deconstruir ideas y actitudes estigmatizadoras y excluyentes y para construir nuevos principios y normas, que parten de un nuevo modelo social, que se basa en los derechos humanos.

Hoy la idea de dignidad se complementa por sensibilidades como la protección del planeta y otros retos de la Humanidad, que ponen en entredicho la posición central del ser humano. Visiones más holísticas sobre los derechos humanos como la de los pueblos indígenas podrían complementar o contribuir a algunos cambios de la visión occidental de los derechos humanos. Es una concepción que puede aportar innovaciones para los derechos humanos en un diálogo intercultural que podría ser conveniente para un cambio de modelo en un mundo sostenible. Se podría complementar la idea del hombre centro del mundo con otros valores que lo situasen como parte de un mundo que debe ser sostenible, lo que plantea un reto relevante. Se está abriendo paso una conciencia de la necesidad de cuidar el planeta, desde una nueva visión de los derechos humanos en la línea de la noción de desarrollo sostenible. Esta visión puede aportar novedades en la evolución de los derechos humanos. Es algo ampliamente compartido no solo desde la idea laica de los derechos humanos sino desde las culturas y religiones. Así, como botón de muestra la encíclica Laudato $\mathrm{Si}$. Sobre el cuidado de la casa común ${ }^{20}$, en línea con la conocida Pacem in terris (del Papa Juan XXIII), hace un "llamamiento a la búsqueda de un desarrollo sostenible e integral" (p. 18), a un "diálogo sobre como construir el planeta", a la necesidad de una "solidaridad universal nueva" (...).

Esta renovación puede llevar también al desarrollo de nuevas generaciones de derechos humanos. El debate sobre las generaciones de derechos humanos debe tener en cuenta que no todos tienen la misma estructura. Los derechos de primera y segunda generación son derechos que tienen la misma estructura de titulares, contenido y exigibilidad en el orden interno y en el internacional. Las otras generaciones de derechos tienen titulares y contenidos distintos, que difícilmente pueden equipararse a los derechos internos o en la Unión Europea. La preocupación por los denominados nuevos derechos no puede sustituir la existente por los viejos, que no están asegurados. Actualmente hay muchos debates sobre los derechos de la población LGTB, lo que está en el centro de

${ }^{19}$ De Lorenzo, R., et al., Fundamentos del derecho de la discapacidad, Thomson Reuters, 2020, en prensa.

${ }^{20}$ Esta encíclica pare de identificar los que "pasa en nuestra casa común”, como consecuencia de la contaminación y de la cultura del descarte, considera el clima un bien común, analiza problemas como el del agua, la pérdida de biodiversidad, el deterioro de la calidad de vida humana y degradación social, la inequidad planetaria, la debilidad de las reacciones Laudato Si. Sobre el cuidado de la casa común, Carta Encíclica de S.S. Francisco. 
la agenda. No estamos en estos casos necesariamente ante nuevas generaciones de derechos, sino ante la aplicación de los ya existentes a personas que son objeto de determinadas discriminaciones y que pueden exigir el desarrollo de normas específicas, en lo que se ha denominado el proceso de especificación. Así, para entender la cuestión de los derechos de la población LGTB, el género tiene que ver con ideas que una cultura desarrolla desde la diferencia anatómica y la identidad de género -indica Romero Campoy ${ }^{21}$ - es la autoidentificación que uno hace de sí respecto de los roles conforme a las tesis de lo masculino y lo femenino que la sociedad ofrece.

Estos desarrollos plantean muchas cuestiones y en la propia Unión Europea su reconocimiento será un proceso lento y llevará tiempo. En la Unión Europea ha avanzado mucho el reconocimiento de los derechos de los homosexuales, pero es algo reciente, de los últimos veinte años. Estos desarrollos para extenderse tanto en el derecho comparado como en el derecho internacional llevarán tiempo y serán el resultado de un proceso de decantación progresiva de la sociedad, si llega a producirse. Hasta tanto se produzca habrá muchas normas de soft law, como los principios de Yoguakarta (2004), sobre la aplicación del DIDH en relación con la orientación sexual y la identidad de género.

En ocasiones el proceso se acelera, pues la identidad de género puede considerarse un aspecto de la propia personalidad, dimensión de la dignidad y de la libertad, valores y principios ya reconocidos en los tratados. La corte interamericana ha considerado que la identidad de género esta vinculada a la libertad y a la posibilidad de todo ser humano de autodeterminarse y ejercer libremente las opciones que dan sentido a su existencia, conforme a sus convicciones, así como al derecho a la vida privada. Para la corte el reconocimiento de la identidad de género está vinculado a la idea de que el sexo y el género deben ser percibidos como parte de una construcción identitaria que es resultado de la decisión libre y autónoma de cada persona, siendo un elemento constitutivo y constituyente de la identidad de las personas. Por ello el reconocimiento de la identidad de las personas es una de las medidas que facilita el ejercicio de los derechos a la personalidad jurídica. Posee, indica, un valor instrumental para el ejercicio de otros derechos y su plena vigencia fortalece la democracia y los derechos y libertades ${ }^{22}$.

El soft law juega un papel importante como punto de partida de nuevos derechos. Los principios rectores empresas y derechos humanos, el pacto mundial de migraciones, los objetivos de desarrollo sostenible, pueden ser una alternativa a la juridificación de los derechos, lo que sería un retroceso. Tampoco la UE ejerce su liderazgo en los tratados de derechos humanos universales donde

${ }^{21}$ Trabajo de doctorado de D Romero Campoy, especialista en derechos humanos del Instituto de derechos humanos Bartolomé de las Casas, noviembre de 2020

${ }^{22}$ Opinión consultiva c-24 de 24-XI-2017 de la Corte interamericana sobre identidad de género y no discriminación a personas del mismo sexo.

Araucaria. Revista Iberoamericana de Filosofia, Política, Humanidades y Relaciones Internacionales, año $22, \mathrm{n}^{\circ} 45$. Tercer cuatrimestre de 2020. Pp. 27-50. ISSN 1575-6823 e-ISSN 2340-2199 https://dx.doi.org/10.12795/araucaria.2020.i45.02 
apenas se ha comprometido por una mínima parte y no se ha sometido ni a los mecanismos de control de Naciones Unidas ni al Tribunal europeo de derechos humanos. La Unión Europea debiera hacerlo, contribuyendo además a cambiar y reforzar esos sistemas internacionales. De un lado a despolitizar los mecanismos de las Naciones Unidas, reforzar su independencia, neutralidad y valor jurídico; de otro lado a la creación de Tribunales internacionales que al igual que garantizan la supervisión de los Estados lo hicieran con otras Instituciones como la propia Unión, aunque se adapten a este ordenamiento que por autónomo que sea no es independiente del orden internacional. El camino de los derechos humanos resulta de un proceso largo, de un camino, en el sentido lorquiano.

En ese iter la UE también debería evitar la sustitución de la lógica del Estado de derecho democrático por un Estado de derecho privado desprovisto de referencias filosóficas a los derechos humanos, reducido a un código de reglas basado en la eficacia, como indica Jauregui ${ }^{23}$. Otro reto proviene de la emergencia de los actores no estatales ${ }^{24}$ que ha llevado a que se muestren insuficientes los planteamientos clásicos ${ }^{25}$. El edificio de los derechos humanos se ha hecho con la idea de limitar el poder del Estado frente al individuo, o de garantizar a este un mínimo de prestaciones por parte de aquél. Pero el binomio Estado-persona resulta insuficiente para garantizar la eficacia de los derechos humanos. La Unión Europea tiene también mucho que hacer pues en ella los actores no estatales (empresas, ciudadanos) son también destinatarios directos, sin intermediación del Estado, del derecho de la Unión.

${ }^{23}$ Jauregui, G., "La emergencia de un nuevo orden jurídico-institucional: el Estado y la Constitución en la era de la globalización”, La humanidad amenazada: gobernar los riesgos globales, Innerarity, D, Solana, J., (Eds), Paidós, 2011, pp. 237-267, p. 254.

${ }^{24}$ Vid. Fernández Liesa, C., "Los actores no estatales y el Derecho internacional de los derechos humanos", Derechos y libertades, nº 41, época II, junio de 2019, pp. 117-149.

25 Vid. Bailliet, C., Non State actors, soft law and protective regimes. From the margins, Cambridge University Press, 2014, pp. 318 ss; Bermejo García, R., "Las empresas transnacionales como actores y sujetos potenciales en la sociedad internacional", Barranco, C., Celador, O., Vacas, F., (Coords), Perspectivas actuales de los sujetos de derecho, Colección Peces-Barba, n 2, Dykinson, 2012, pp. 93 ss; CLAPHAM, A., Human rights obligations of non-State actors, Oxford, 206; Colas, A., Mabee, B., (Coords), Mercenaries, pirates, bandits and Empires. Private violence in historical context, Hurst\&Company, 2010; Fernández Liesa, C., López-Jacoiste, E., (Coords), Empresas y derechos humanos, Thomson Reuters Aranzadi, 2018, pp. 485-507; Heere, W., From government to governance. The growing impact on non State actors in the international and European legal system, Asser Press, 2004; Hyeran, Compliant rebels (problems of international politics), Cambridge University Press, 2017; Mills, K., Karp, D., Human rights protection as global politics, responsibility of States and non State actors, 2015; Mariana, T., Accountability under human rights laws of non State actors for genocide and crimes against humanity: individuals, armed groups and corporations, Lambert, 2001; Marrero Rocha, I., "Los actores internacionales en el ámbito de la no proliferación y el desarme nuclear: características e impacto", REDI, vol. LXIV, núm 1, 2012, pp. 73-102; Murray, D., Human rights obligations of non State actors armed groups in international law, Hart, 2018; Nykanen, Fragmented State power and forced migration. A Study on non State actors in refugee law, Martinus Nijhiff publishers, 2012; Pushparajah, N., Human rights obligations of armed non State actors in the international armed conflicts, 2016; Rodenhauser, Organizing rebellion: non State armed groups under international humanitarian law, human rights law and international criminal law, Oxford, 2018;

Araucaria. Revista Iberoamericana de Filosofia, Política, Humanidades y Relaciones Internacionales, año $22, \mathrm{n}^{\circ} 45$. Tercer cuatrimestre de 2020. Pp. 27-50. ISSN 1575-6823 e-ISSN 2340-2199 https://dx.doi.org/10.12795/araucaria.2020.i45.02 


\section{Renovar los derechos humanos en la acción exterior.}

Entre los principios de la acción exterior que se reconocen desde el tratado de Maastricht, y que aparecen en el Tratado de Lisboa entre los valores de la UE (art. 2 y 3 ) y en los principios comunes a toda la acción exterior está la promoción de los derechos humanos, el estado de derecho, la democracia y los derechos de las minorías. Esto ha dado lugar a amplias reflexiones sobre las denominadas cláusulas democráticas. No creo que sea conveniente volver a estas reflexiones.

En primer lugar, vamos a ver cómo la evolución de la acción exterior presta menos atención al valor de la solidaridad internacional que sería probablemente el mayor apoyo que la UE presta a los derechos humanos en el mundo. La UE se ha posicionado en el último medio siglo como uno de los primeros actores comerciales y solidarios, y ahora pretende ser un actor global. El contexto actual es especialmente difícil con el Brexit, la crisis del multilateralismo, la emergencia de nuevos actores, la crisis comercial y las difíciles relaciones entre Estados Unidos y la UE. La evolución de la acción exterior europea y de sus acuerdos y la renegociación de los mismos no está basada en el principio de solidaridad ni en la protección de los derechos humanos. Todo lo más se ha pasado a una reciprocidad asimétrica donde antes no había reciprocidad, y se ha sustituido lo "preferencial" por la apertura recíproca de los mercados.

Así sucede en relación con los países de África, Caribe y Pacífico, donde la UE va hacia un modelo más comercial, desde el previo modelo de trato especial y diferenciado. A tal efecto se ha roto la unidad al hacer subgrupos (África Central, occidental, oriental y austral) en los que se ha ido pasando de un modelo de trato especial a otro más liberal. En relación con Asia y América Latina, que eran los grandes olvidados del pasado se están fortaleciendo las relaciones también con la misma idea y muy diferentes resultados. Cabe destacar los recientes acuerdos con Japón (2017, en vigor, 2019), Singapur (2014), Vietnam (2015) que son los denominados megarregionales, y las negociaciones actuales con India (desde 2016) y China, o la sustitución del acuerdo con Asean por acuerdos bilaterales. Por no hablar de las relaciones con los países mediterráneos, vecinos, industrializados, y del este. El panorama es de gran incertidumbre y sin un modelo solidario pro derechos humanos.

La globalización y la lucha comercial en un escenario neoliberal han llevado a un cambio de prioridades en las que la Unión Europea es difícil que pueda mantener con credibilidad una imagen y un discurso de derechos humanos y de solidaridad, que la habían caracterizado a lo largo de su acción exterior. Sería conveniente que este perfil continuase y se renovase en una orientación pro derechos humanos. 
En segundo lugar, hay que tener en cuenta el papel que puede hacer la UE en impulsar un diálogo transcivilizatorio que haga más aceptado y consensuado el sistema jurídico-político internacional y los derechos humanos. El orden internacional ha sido un producto de la cultura europea. La universalización del Derecho internacional bajo el estándar cultural y civilizatorio europeo beneficiaba al imperialismo europeo. El derecho y la organización del mundo se formaron sobre la base de los intereses y de las concepciones de los Estados de cultura europea. En el nacimiento del moderno derecho internacional hay una conexión entre los rasgos del derecho internacional y los intereses del imperialismo europeo ${ }^{26}$.

Onuma Yasuaki ${ }^{27}$ ha propuesto una perspectiva transcivilizacional, que parta del reconocimiento de la multiplicidad de civilizaciones y culturas. La Unión Europea podría hacer mucho por fortalecer un orden internacional que sea fruto de una cultura compartida en el respeto a la diversidad. Los derechos humanos más que constituir una matriz de dominación son un punto de encuentro intercultural que debe ser perfeccionado. La UE debe apostar por la tesis de la universalidad como estándar mínimo. Rawls indicado que "los derechos humanos son un elemento central de una construcción aplicable al DI, en la medida en que establecen los límites morales al pluralismo entre los pueblos"28. La tesis del universalismo como estándar mínimo es la que cabe deducir de los principales tratados de derechos humanos y de la interpretación que de los mismos hacen los órganos internacionales de derechos humanos. El problema es la interpretación intolerante y radical que se hace desde algunas perspectivas fundamentalistas ideológicas, económicas, nacionalistas y religiosas. La tensión entre la universalidad y la diversidad entre los diferentes sistema socio-culturales debe resolverse a favor de la universalidad del estándar mínimo. En esta línea la conferencia de Viena de derechos humanos (1993) indicó que "el carácter universal de los derechos humanos y libertades no admite dudas” (Parte I de la Declaración, pár. 1.1).

La Unión europea podría impulsar un diálogo de civilizaciones en torno a los elementos cardinales de los derechos humanos en el derecho internacional. Un orden internacional ${ }^{29}$ que sea fruto de una cultura compartida en el respeto a la diversidad cultural es la mejor vía para que sea un orden respetado y eficaz,

\footnotetext{
${ }^{26}$ Bowden, B., "The colonial origins of international law. European expansion and the classical standard of civlizations", Journal of history of the international law, vol. 7, $\mathrm{n}^{\circ} 1,2005$, pp. 1.23, Fiusch, J., "Power or weakness? On the causes of the worldwide expansion of European international law, Journal of history of international law, pp. 21 ss, 2004.

${ }^{27}$ Yasuaki, O., "A transcivilizational perspectiva on international law", RCADI, La haya, $\mathrm{n}^{\circ} 342$, 2009.

${ }^{28}$ Rawls, J., "El derecho de gentes", Isegoría, Revista de filosofía moral y política, n 16 , mayo de 1997, pp. 5-37.

${ }^{29}$ Vid. sobre sobre mi libro Cultura y derecho internacional, Universidad de Alcalá de Henares, 2012, pp. 41 ss.
} 
que contribuya a la solución de los problemas de la humanidad. Se necesitaría un impulso consciente y mayor en esta dirección. Hay que ser autocríticos en occidente, de manera diferente a la teoría crítica, pero siendo conscientes de que ha habido una perspectiva occidental dominante que desde un sentido de universalidad y de diversidad, que no de superioridad, requiere un cambio, en la tradición de Bartolomé de las Casas, Montaigne, Voltaire, Rousseau o Diderot $^{30}$.

\section{Apoyar la judicialización de los derechos humanos.}

La justicia internacional refleja el viejo sueño de la paz a través del derecho. Como indica el lema del Tribunal para la Antigua Yugoslavia su creación no se fundamenta en la máxima fiat justicia et pereat mundus, sino la máxima de Hegel fiat justitia ne pereat mundus. Hay una estrecha relación entre la paz, los derechos humanos y la judicialización de las relaciones internacionales.

LaUnión Europea apoyó el desarrollo de Tribunales penales internacionales, en un gran avance en la lucha contra la impunidad de las grandes violaciones de derechos humanos. Dese el Tribunal de Nuremberg, se inicia el camino hacia un Tribunal internacional penal. Hubo que esperar a la caída del muro y al inicio de la guerra en el territorio de la Antigua Yugoslavia para que en 1994 la CDI (Comisión de Derecho internacional) aprobase un proyecto de estatuto de Tribunal penal internacional, complementado en 1996 con otro proyecto de código de crímenes contra la paz y la seguridad de la Humanidad. El código de crímenes de 1996 era muy restrictivo en los tipos penales incluidos.

En el proyecto se tipificaban los crímenes de agresión, de genocidio, contra la humanidad, contra el personal de Naciones Unidas y los crímenes de guerra. Salvo el penúltimo, los demás tienen vigencia consuetudinaria. Los demás no se incluyeron pues había dudas sobre el respaldo de los gobiernos, y por las dificultades en su concreta tipificación y elementos. Así sucedió con los crímenes de intervención, la dominación colonial, el reclutamiento, la utilización, financiación y entrenamiento de mercenarios, el tráfico de estupefacientes, el terrorismo o los daños intencionales y graves al medio ambiente.

En este contexto se crearon los Tribunales ad hoc de la Antigua Yugoslavia y Ruanda, y también los denominados Tribunales especiales del Líbano, Sierra Leona o Camboya. Como resultado de todo ello el mayor avance vino con la creación de la Corte Penal internacional, lo que abría, según dijera C Bassiouni,

\footnotetext{
${ }^{30}$ En esta línea, Morin, E., "Resistir a lo intolerable", AAVV, Democracia y responsabilidad. Las caricaturas de Mahoma y la libertad de expresión, Nais, S. (ed) Galaxia Gutemberg, 2008, pp. 45-60 y 55 .
}

Araucaria. Revista Iberoamericana de Filosofia, Política, Humanidades y Relaciones Internacionales, año 22, $\mathrm{n}^{\circ} 45$. Tercer cuatrimestre de 2020. Pp. 27-50. ISSN 1575-6823 e-ISSN 2340-2199 https://dx.doi.org/10.12795/araucaria.2020.i45.02 
presidente del Comité de redacción del Estatuto de la Corte, una nueva era en la historia de la justicia penal internacional.

Junto a la justicia penal internacional hay órganos internacionales de derechos humanos universales (mecanismos de Naciones Unidas), regionales (Europa, América, África), de integración o de otras materias que sin ser de derechos humanos afrontan cuestiones de derechos humanos, como el CIADI, el órgano de apelación de la OMC, los tribunales de arbitraje, los tribunales administrativos, los tribunales de la opinión pública etc.

Todo esto ha roto el binomio soberanía-jurisdicción, pues los tribunales internacionales no forman parte del poder soberano de un Estado, ni de un inexistente Estado mundial. Cada tribunal es el resultado de un pacto entre Estados cuyo objeto es crear un Tribunal, que será un sistema autocontenido, un self contained system, que no se inserta en una estructura internacional estatal, pues no existe una pirámide kelseniana y los tribunales no tienen relaciones de jerarquía entre sí. El nexo de unión de los Tribunales es su pertenencia a la misma galaxia del orden internacional y su sujeción a las reglas básicas. Estamos pues ante tribunales que tienen una jurisdicción consensual, fruto del consentimiento de los Estados ${ }^{31}$, elemento clave en todo el ciclo vital del orden internacional, desde el momento de la creación de las normas hasta su aplicación, lo que introduce una importante dosis de relativismo.

De cara al futuro la Unión Europea debería apostar por apoyar la creación de un tribunal internacional de derechos humanos dado que los órganos y mecanismos de Naciones Unidas no tienen tal naturaleza. Suiza en 2008 hizo una propuesta ${ }^{32}$. Estaría compuesta por 21 jueces elegidos por entre 3 y 9 años, y tendría su sede en Ginebra. Esta propuesta, así como otra de Túnez (de 2013) de crear una Corte Constitucional internacional suponen un implícito reconocimiento de la debilidad de los mecanismos de protección de derechos humanos universales y su objeto central sería contribuir a incrementar la eficacia de los derechos humanos. Bien haría la UE en impulsar ese nuevo Tribunal, cuyo estatuto debería negociarse con un espíritu de incorporación de otras perspectivas y culturas, así como de someterse ella misma al control del $\mathrm{TEDH}$, con las reformas que ello requiera.

\footnotetext{
${ }^{31}$ El ejercicio de la jurisdicción no es obligatorio, sino que depende de la voluntad de las partes, de su consentimiento (Asunto reparación de daños sufridos al servicio de Naciones Unidas, REC, TIJ, 1949, pp. 181 ss)

32 Vid. Callejón, L., "Cour mondiale des droits de 1'homme, Cour constitutionnele international. Analyse compare de deux projets d'inspiration cosmopolotique", Le cosmopolitisme juridique, Olivier de Frouville (dir), Ed. A. Pedone, 2015, pp. 329-351.
} 


\section{Apoyar la sostenibilidad de los derechos humanos}

¿Está consolidado el acervo de los derechos humanos? No estamos a salvo de que el patrimonio de los derechos humanos pueda sufrir una regresión. Muchos derechos de primera y segunda generación tienen todavía una aplicación poco eficaz, grandes deficiencias, mientras la doctrina se preocupa de nuevas perspectivas, avances intelectuales muchas veces solo aplicables en espacios muy limitados y para un grupo de personas muy pequeño. Los derechos humanos se abrieron paso siempre con dificultad. La propia UE sufre un debilitamiento de la eficacia de los derechos humanos, agudizada en las crisis económicas de 2008 y la pandemia del coronavirus. Además, la globalización ha puesto en duda los derechos sociales. Una visión liberal de los derechos humanos siempre apostó más por los de primera generación, pero se aceptó el Estado social.

La globalización puso en duda la sostenibilidad y el papel del Estado como garante de los derechos sociales. Las actuales tendencias doctrinales dan por hecho la consolidación intelectual y real de estos derechos, lo que sin embargo no es un dogma de fe. La tendencia a fijarse en nuevos derechos, sobre los que no existe un mínimo consenso, puede evidenciar más debilidad que fortaleza. Por ejemplo, ahora se plantea si un río tiene derechos. Tal vez instituciones como las confederaciones hidrográficas del derecho español cumplen igualmente con la función protectora de la cuenca hidrográfica y del ecosistema, sin necesidad de articular nuevos derechos humanos, por su propia naturaleza casi imposibles de construir sin deconstruir previamente el acervo de derechos existente.

La globalización neoliberal y el debilitamiento del Estado, la degradación de la democracia liberal, el nacionalismo y el populismo han puesto en crisis la fortaleza de los derechos humanos. Las posiciones de algunas potencias como Estados Unidos, China, Rusia, la debilidad europea o el Islam radicalizado han llevado el viejo sueño ilustrado de los derechos humanos a una crisis en la que sería necesario reconquistar el sentido de los derechos humanos ${ }^{33}$.

Hasta el momento tanto dentro de los Estados como en la Comunidad internacional el único modelo de derechos humanos que ha existido ha sido el liberal. Los modelos comunistas no han permitido que se desarrollen valores como la libertad o el pluralismo, por lo que propiamente no cabría afirmar que respetasen los derechos de primera generación. En el ámbito internacional los derechos se han desarrollado desde esa perspectiva.

Destruir el patrimonio internacional de los derechos humanos en busca de un paraíso mejor creo que es un camino muy peligroso, que se ha intentado ya en muchas ocasiones, a la búsqueda de un hombre nuevo, desligado de las

33 Dupuy, P.M, "La communauté internationale. Une fiction", Ordre juridique et desordre international, A. Pedone, Paris, 2018.

Araucaria. Revista Iberoamericana de Filosofia, Política, Humanidades y Relaciones Internacionales, año 22, $\mathrm{n}^{\circ} 45$. Tercer cuatrimestre de 2020. Pp. 27-50. ISSN 1575-6823 e-ISSN 2340-2199 https://dx.doi.org/10.12795/araucaria.2020.i45.02 
ataduras estructurales o de las matrices de subordinación. Por ello mejor es seguir apostando por los valores de igualdad, libertad, solidaridad, pluralismo.

Ello no obstante hay que impulsar el modelo volviendo a lo básico, a los principios, a la dignidad, los grandes tratados de derechos humanos, a los problemas básicos de los seres humanos. Hay que reconquistar los derechos humanos, y revivirlos para el siglo XXI, mejorar su medio ambiente y el apoyo político y social sobre los mismos. También habría que reimpulsar nociones que fueron motoras en el pasado, pero que hoy han dejado de serlo, como la de patrimonio de la humanidad, crímenes contra la humanidad, género humano etc. Es necesario renovar el consenso internacional sobre los derechos humanos y no darlo como algo hecho, como un dogma.

El multipolarismo actual no permite asegurar una concepción común de los derechos humanos, que hay que refortalecer. Los derechos humanos siempre avanzaron entre sombras y luces, por lo que hay que confiar en que su destino seguirá siendo iluminado por la idea de progreso.

\section{La Agenda 2030 y los derechos humanos}

Una nueva utopía que ha aparecido en tiempos recientes es la denominada agenda 2030 y los Objetivos de desarrollo sostenible tienen mucha relevancia para los derechos humanos. Muchos ODS tienen relación directa con los derechos humanos como el 1 (pobreza), 2 (hambre), 3 (vida sana), 4 (educación), 5 (igualdad de género), 6 (agua), 8 (crecimiento inclusivo), 10 (desigualdad), 13 (clima), 16 (sociedades e instituciones pacíficas e inclusivas). Es decir, de 17 objetivos más de la mitad se refieren expresamente a los derechos humanos. Estamos ante la nueva aventura de los derechos humanos.

La Agenda 2030 es un gran viaje a favor de la dignidad humana en el que nadie debe quedarse atrás, ha señalado la $\mathrm{AGONU}^{34}$. Tiene su origen en la noción de desarrollo sostenible, que busca satisfacer las necesidades de las generaciones presentes sin comprometer las futuras. Este enfoque intergeneracional empieza con el Informe Nuestro futuro común (Informe Bruntland), de la Comisión mundial sobre medio ambiente y desarrollo, y posteriormente se complementa con la visión medioambiental, sobre todo desde la Cumbre de Río de Janeiro de 1992, y social (Cumbre de Johanesburgo, de desarrollo sostenible, de 2002). El tercer pilar es la sostenibilidad económica.

${ }^{34}$-Transformar nuestro mundo: la Agenda 2030 para el desarrollo sostenible, Res aprobada por la Asamblea General de Naciones Unidas el 25 de septiembre de 2015. Vid. también Fernández Liesa, C., "Transformaciones del Derecho internacional por los Objetivos de desarrollo sostenible", Análisis y comentarios de los objetivos de desarrollo sostenible, Fdez Liesa, C., Manero Salvador, A., (Dirs.), Thomson Reuters Aranzadi, 2017, pp. 29-61. 
La hoja de ruta tiene muchas páginas en blanco y múltiples interrogantes. Estamos ante un horizonte que puede ser una frustración. Los logros se medirán una vez que esté más avanzado el camino. De cumplirse los objetivos el mundo se transformaría a mejor. Los ODS pueden completar la dinámica del DIDH con la metodología de los objetivos, que puede constituir un buen complemento si no los desjuridifica. Estamos ante una idea más vinculada a la noción de proceso que de derechos humanos propiamente.

Los ODS suponen algunas transformaciones para el derecho internacional, que se orienta a una finalidad, establece un horizonte mítico-utópico, en el sentido de proyecto a realizar, lo que puede ser un motor de transformación. El desarrollo sostenible forma parte de la utopía de la Comunidad internacional contemporánea. Esto no nos sitúa al margen de una visión socio-histórica o real del ordenamiento, pues un exceso de realismo puede ser negativo. La legitimidad anunciadora, decía Dupuy ${ }^{35}$ contribuye a transformar el derecho en el sentido de la justicia. El DI se desarrolla con referencia a mitos universales que en ocasiones se encarnan en el tejido normativo, al menos parcialmente. La utopía invoca el cambio normativo, normalmente en interés de los sujetos más débiles en el ordenamiento, o de intereses generales, como sucede con la noción de desarrollo sostenible. De tal modo que las utopías otorgan al derecho una dimensión ideológica que proyecta representaciones y referencias intelectuales y morales, que se añaden a su dimensión organizativa y de registro (S. Sur). La dimensión utópica del DI es de los débiles y tiende a corregir la desigualdad, mientras que en su dimensión organizativa es un derecho de iguales y en su dimensión de registro es un derecho de los poderosos (Sur, p. 41).

\section{Derechos humanos, populismo y nacionalismo en la UE}

Los grandes enemigos para los derechos humanos en la UE son en la actualidad el populismo y el nacionalismo, que llevan a un deterioro de la democracia liberal y de la idea de ciudadanía en sentido ilustrado. El fenómeno afecta a muchos países, algunos de manera especialmente significativa, como Hungría con V. Orban.

Mounk $^{36}$ ha analizado el ascenso de la democracia iliberal concebida como una democracia sin derechos, donde se produce una rebelión contra el pluralismo étnico cultural y la falta de respeto al derecho y a las instituciones, al Estado de derecho y a la Constitución. Buen botón de muestra en la Unión Europea es el asunto C-618, ST Justicia, Gran Sala, de 24 de junio de 2019 el TJUE condenó a Polonia, una vez

${ }^{35}$ Dupuy, R.J., La Communauté internationale entre le mythe et l'histoire, Economica, París, 1986, pp. 119 ss.

${ }^{36}$ Mounk, Y., El pueblo contra la democracia. Por qué nuestra libertad está en peligro y como salvarla, Paidós, Barcelona, 2018.

Araucaria. Revista Iberoamericana de Filosofí, Política, Humanidades y Relaciones Internacionales, año 22, $\mathrm{n}^{\circ} 45$. Tercer cuatrimestre de 2020. Pp. 27-50. ISSN 1575-6823 e-ISSN 2340-2199 https://dx.doi.org/10.12795/araucaria.2020.i45.02 
que la Comisión había iniciado un procedimiento por incumplimiento del art. 19 TUE (1, segundo) en relación con el art. 47 de la Carta DDFF al haberse reducido la edad de jubilación de los jueces del Tribunal Supremo y al atribuir al Presidente de la República la facultad discrecional para prorrogar la función jurisdiccional de los jueces una vez alcanzada la edad de jubilación. Para el Tribunal el principio de tutela judicial efectiva exige una justicia independiente. Para que el TS pueda garantizar la tutela es necesario preservar su independencia, que está integrada en el contenido esencial del derecho a la tutela judicial efectiva y en el derecho a un proceso equitativo. El principio de inamovibilidad exige que los jueces permanezcan en el ejercicio de sus funciones en tanto no hayan alcanzado la edad de jubilación forzosa o hasta que termine el mandato, si tiene una duración determinada. Polonia no ha dado razones objetivas sobre la necesidad de la medida, lo que no respeta el principio de proporcionalidad. Se está ante un terminación anticipada y definitiva de la carrera judicial de los interesados, no justificada por un objetivo legítimo, lo que viola el principio de inamovibilidad del juez, inherente a su independencia.

Además, este deterioro democrático se refleja en el incremento del nacionalismo que lleva también a no respetar el pluralismo social o informativo, no respetar la ley y la constitución, no respetar la separación de poderes o la neutralidad de las instituciones. Marlene Wind ${ }^{37}$ pone a Cataluña como un ejemplo de tribalización de la Unión Europea, en una tendencia más general a levantar los puentes levadizos (Kissinger se refiere a la ciudad amurallada) como consecuencia de las políticas identitarias y de la reducción de la democracia a la mera voluntad del pueblo.

Se está deteriorando la idea de ciudadanía al exaltarse sin freno y por ello en exceso los particularismos étnicos, nacionales o religiosos, que habrían acabado con la idea de ciudadanía, como ya vienen reflexionado desde hace tiempo autores como Touraine o Sartori ${ }^{38}$. Más recientemente Fukuyama ha indicado que las democracias liberales no acaban de saber resolver el problema del thymós (la parte del alma que anhela el reconocimiento de la dignidad) ${ }^{39}$; no estarían siendo capaces de resolver la cuestión de la búsqueda de formas parciales de reconocimiento (nación, religión, secta, raza, origen étnico o sexo). Esto habría producido, indica, políticas de resentimiento de los miembros de grupos, que se ven ofendidos o agraviados. Se ha pasado de políticas de reconocimiento a políticas de resentimiento. Es el caso de los nacionalismos radicalizados, que ponen en serio peligro el pluralismo, propio de cualquier sociedad libre, que debe ser plural, como indica Sartori (p. 14).

${ }^{37}$ Wind, M., La tribalización de Europa. Una defensa de nuestros valores liberales, Espasa, 2019, pp. 9 ss.

38 Touraine, A., ¿Qué es la democracia?, Temas de Hoy, 1994, pp. 34 ss; Sartori, G., La sociedad multiétnica. Pluralismo, multiculturalismo y extranjeros, Taurus, 2001.

39 De otro lado la isotimia sería la exigencia de ser respetado en igualdad de condiciones; y la megalotimia el deseo de ser reconocido como superior. Fukuyama, F., Identidad. La demanda de dignidad y las políticas de reconocimiento, Ed. Deusto, 2019. 
Unos y otros factores han hecho que campe el populismo y se deterioren los valores de la democracia liberal, única en la que han germinado los derechos humanos en términos históricos. El respeto a la ley, la separación de poderes, el pluralismo, la función de control y de formación de la opinión pública de los medios de comunicación, están en crisis por la fuerza del populismo iliberal, por la fuerza de la emoción frente a la razón y por el no respeto de las reglas del juego. En esto la Unión Europea debería tomar un liderazgo mayor, que puede verse debilitado por el incremento de las fuerzas extremistas en los Estados miembros y en el Parlamento Europeo que, sin embargo, están lejos de la mayoría.

\section{Reflexión final}

A lo largo de estas páginas hemos realizado un análisis crítico de la situación de los derechos humanos en la Unión Europea. Nuestra idea es que el sistema de protección de los derechos humanos en la Unión Europea es un sistema de mínimos, con escasa repercusión. Y que por ello si la Unión Europea quiere asumir el papel que le corresponde históricamente de ser un faro para los derechos humanos en el mundo y en el espacio europeo, como lo fue Europa en el pasado, tendría que renovarse y reconquistar los derechos humanos.

Es difícil hacer esto en tiempos en que los populismos y los nacionalismos se han incrementado en el espacio europeo, y además de grandes crisis económicas. Pero hay que hacer de la necesidad virtud. Mantener el legado de la Ilustración y los valores de Europa exige situar a los derechos humanos en el lugar de honor que deben tener en la construcción europea. Tal vez la salida del Reino Unido es una oportunidad en este sentido.

Son muchas las recetas y las líneas de acción que hemos sugerido. Sin duda hay que avanzar en la Europa social, única manera de armonizar socialmente a la Unión Europea y de luchar contra la pobreza y la desigualdad crecientes. También hay que fortalecer el estado de derecho y deslegitimar los populismos y los nacionalismos extremistas que tanto daño hacen a los principios democráticos. Asimismo, hay que impulsar no solo normas sino fundamentalmente políticas y estrategias con estos objetivos, que permitan recuperar una idea de ciudadanía (no en el sentido solo de la ciudadanía europea) vinculada a los derechos humanos, que está en grave deterioro. Reconquistar los derechos humanos requiere mantener y renovar el legado de la Ilustración, renovar la idea de dignidad, impulsar políticas internas e internacionales, contribuir al reforzamiento de la judicialización internacional de los derechos humanos, someterse a los sistemas de control, reforzar la sostenibilidad de los mismos, entre otras muchas. 


\section{Referencias bibliográficas:}

Applebaum A., Gulag. Historia de los campos e concentración soviéticos, Editorial Debate, Barcelona, 2004.

Bachand, R., Les subalternes et le Droit international, Ed. A Pedone, París, 2018.

Bailliet, C., Non State actors, soft law and protective regimes. From the margins, Cambridge University Press, Cambridge, UK, 2014.

Bermejo Garcia, R., "Las empresas transnacionales como actores y sujetos potenciales en la sociedad internacional", en Barranco, C., Celador, O., Vacas, F., (Coords.), Perspectivas actuales de los sujetos de derecho, Colección Peces-Barba, n 2, Dykinson, Madrid, 2012.

Bobbio, N., El tiempo de los derechos, Editorial Sistema, Madrid, 1991.

Bowden, B., "The colonial origins of international law. European expansion and the classical standard of civlizations", Journal of history of the international law, vol. 7, $\mathrm{n}^{\circ} 1,2005$.

Callejón, L., "Cour mondiale des droits de 1'homme, Cour constitutionnele international. Analyse compare de deux projets d'inspiration cosmopolotique", en Frouville, O. de (dir.), Le cosmopolitisme juridique, Ed. A. Pedone, Paris, 2015.

Carrillo Salcedo, J.A., Globalización y orden internacional, Lección inaugural leída en la solemne apertura del curso académico 2004, 2005, de la Universidad de Sevilla, Sevilla, 2004.

Clapham, A., Human rights obligations of non-State actors, Oxford University Press, Oxford, UK, 2006.

Colas, A., Mabee, B., (Coords), Mercenaries, pirates, bandits and Empires. Private violence in historical context, Oxford University Press, USA, 2010.

De Lorenzo, R., et al., Fundamentos del derecho de la discapacidad, Thomson Reuters, Madrid, 2020.

Dupuy, P.M, "La communauté internationale. Une fiction", Ordre juridique et desordre international, A. Pedone, París, 2018.

Dupuy, R.J., La Communauté internationale entre le mythe et l'histoire, Economica, París, 1986.

Fernández Liesa, C., "Transformaciones del Derecho internacional por los Objetivos de desarrollo sostenible", en Fernández Liesa, C., Manero Salvador, A., (Dir), Análisis y comentarios de los objetivos de desarrollo sostenible Thomson Reuters Aranzadi, Cizur, Menorca, 2017.

Fernández Liesa, C., Cultura y derecho internacional, Universidad de Alcalá de Henares, Alcalá de Henares, 2012. 
Fernández Liesa, C., "Los actores no estatales y el Derecho internacional de los derechos humanos", Derechos y libertades, n 41, época II, junio de 2019.

Fernández Liesa, C., López-Jacoiste, E., (Coords.), Empresas y derechos humanos, Thomson Reuters Aranzadi, 2018.

Fernández Sánchez, P.A., García Roca, F.J., Integración europea a través de derechos fundamentales: de un sistema binario a otro integrado, VVAA, Centro de estudios políticos y constitucionales, Madrid, 2009.

Fernández Sánchez, P.A. (coord.), La obra jurídica del Consejo de Europa (En conmemoración del 60 aniversario del Consejo de Europa), Ed. Gandulfo, Sevilla, 2010.

Ferrajoli, L., Manifiesto por la igualdad, Editorial Trotta, Madrid, 2019.

Fiusch, J., "Power or weakness? On the causes of the worldwide expansion of European international law, Journal of history of international law, 2004.

Fukuyama, F., Identidad. La demanda de dignidad y las politicas de reconocimiento, Ed. Deusto, Grupo Planeta, Barcelona, 2019.

González Soriano, J.A., "La teoría crítica de la Escuela de Frankfurt como proyecto histórico de racionalidad revolucionaria", Revista de filosofía, vol. $27, \mathrm{n}^{\mathrm{o}} 2,2002$.

Habermas, J., Escritos sobre moralidad y eticidad, Paidós, Barcelona, 1991.

Heere, W., From government to governance. The growing impact on non State actors in the international and European legal system, Asser Press, 2004;

Hyeran, Compliant rebels (problems of international politics), Cambridge University Press, 2017.

Jáuregui, G., "La emergencia de un nuevo orden jurídico-institucional: el Estado y la Constitución en la era de la globalización”, en INNERARITY, D, SOLANA, J., (Eds), La humanidad amenazada: gobernar los riesgos globales, Paidós, Barcelona, 2011.

Kepel, H., La revancha de Dios, Ciencia política, Alianza Editorial, Madrid, 2005.

Mariana, T., Accountability under human rights laws of non State actors for genocide and crimes against humanity: individuals, armed groups and corporations, Lambert, USA, 2001.

Marrero Rocha, I., "Los actores internacionales en el ámbito de la no proliferación y el desarme nuclear: características e impacto", REDI, vol. LXIV, $\mathrm{n}^{\circ} 1,2012$.

Mills, K., Karp, D., Human rights protection as global politics, responsibility of States and non State actors, Palgrave, MacMillan, UK, 2015.

Morin, E., "Resistir a lo intolerable", en NAIS, S., (ed), Democracia y responsabilidad. Las caricaturas de Mahoma y la libertad de expresión, Galaxia Gutemberg, Barcelona, 2008. 
Mounk, Y., El pueblo contra la democracia. Por qué nuestra libertad está en peligro y como salvarla, Paidós, Barcelona, 2018.

Murray, D., Human rights obligations of non State actors armed groups in international law, Hart, Oxford, UK, 2018.

Nykanen, Fragmented State power and forced migration. A Study on non State actors in refugee law, Martinus Nijhiff Publishers, The Hague, 2012;

Peces-Barba, G., Etica, poder y derecho. Reflexiones ante el fin de siglo, Centro de Estudios Constitucionales, Madrid, 1995.

Peces-Barba, G., La dignidad de la persona humana desde la filosofía del derecho, Dykinson, Madrid, 2002.

Pele, A., La dignidad humana. Sus orígenes en el pensamiento clásico, Instituto de derechos humanos Bartolomé de las Casas, Dykinson, Madrid 2010.

Pinker, S., En defensa de la Ilustración, Paidós, Barcelona 2018.

Pushparajah, N., Human rights obligations of armed non State actors in the international armed conflicts, Wolf Legal Publishers, Oisterwijk, Netherlands, 2016.

Ripoll Carulla, S., Ugartemendía, J.I., España ante los tribunales internacionales europeos: cuestiones de politica judicial, Instituto Vasco de Administración Pública, Vitoria, 2008.

Rodenhauser, Organizing rebellion: non State armed groups under international humanitarian law, human rights law and international criminal law, Oxford University Press.

Rawls, J., "El derecho de gentes", Isegoría, Revista de filosofía moral y política, $\mathrm{n}^{\circ} 16$, mayo de 1997, pp. 5-37.

Sachs, J., La era del desarrollo sostenible, Deusto, Grupo Planeta, Barcelona, 2016.

Sartori, G., La sociedad multiétnica. Pluralismo, multiculturalismo y extranjeros, Taurus, Barcelona, 2001.

Touraine, A., ¿Qué es la democracia?, en Temas de Hoy, 1994.

Wind, M., La tribalización de Europa. Una defensa de nuestros valores liberales, Espasa, Madrid, 2019.

Yasuaki, O., "A transcivilizational perspectiva on international law", $R C A D I$, La Haya, Netherlands nº 342, 2009. 